\title{
ARTICLE
}

Body composition, energy expenditure and physical activity

\section{Association between risk factors of metabolic syndrome with lung function}

\author{
Yi-Yen Lee ${ }^{1,2} \cdot$ Yu-Chung Tsao ${ }^{3} \cdot$ Chih-Kai Yang ${ }^{4} \cdot$ Chung-Hsun Chuang ${ }^{4,5} \cdot$ Wei Yu ${ }^{6}$ Jih-Chang Chen ${ }^{5}$ \\ Wen-Cheng $\mathrm{Li}^{6,7}$
}

Received: 20 February 2016 / Revised: 12 September 2018 / Accepted: 16 November 2018 / Published online: 19 August 2019

(c) Springer Nature Limited 2018

\begin{abstract}
Background/Objectives Increased evidence suggests that metabolic syndrome (MetS) is correlated with lung function impairment. This study aimed to explore the associations between MetS risk factors and the lung function.

Subjects/Methods The cross-sectional study included 6945 participants attending health examination between 2010 and 2012 in Taiwan. MetS was assessed according to the criteria of National Cholesterol Education Program III. Spirometric parameters were measured to define lung function. The relationships were tested using multiple linear regression and logistic regression analyses.

Results The prevalence of MetS was significantly higher in males (16.2\%) than females (3.8\%). Although the prevalence of restrictive lung disease (RLD) was comparable between genders (20.7 and 21.0\%), males with co-existent MetS had a higher prevalence of RLD than females (27.4 vs. $18.0 \%$ ). Abdominal obesity, indicated by waist circumference (WC) and weightto-height ratio (WHtR), was the most significant factor associated with lung function decline. Other components of MetS also showed statistically significant relationships, but very weak, with lung function. There was a trend toward an increased prevalence of RLD with the increasing number of MetS scores in males, independent of age, smoking, and body mass index. Conclusions Abdominal obesity was the key component of MetS associated with mechanical effect on lung function impairment in a prime-age adult population. Although RLD was not associated with increased probability of having MetS, the participants with more MetS scores were at a higher risk of losing lung function.
\end{abstract}

Wen-Cheng Li

620313@adm.cgmh.org.tw

1 Division of Pediatric Neurosurger, Neurological Institute, Taipei Veterans General Hospital, Taipei, Taiwan

2 Faculty of Medicine, National Yang-Ming University, Taipei, Taiwan

3 Department of Occupational Medicine, Chang-Gung Memorial Hospital at Linkou, Taoyuan, Taiwan

4 Department of Emergency Medicine, Xiamen Chang-Gung Hospital, Xiamen, China

5 Department of Emergency Medicine, Chang-Gung Memorial Hospital at Linkou, Taoyuan, Taiwan

6 Department of Health Management, Xiamen Chang-Gung Hospital, Xiamen, China

7 Department of Family Medicine, Chang-Gung Memorial Hospital at Linkou, Taoyuan, Taiwan

\section{Introduction}

Metabolic syndrome (MetS) increases significantly along with obesity has become a pandemic. Studies have shown that Asians seem to have a higher risk to develop MetS at a given level of obesity [1]. MetS, characterized by clustering of abdominal obesity, hypertension, insulin resistance and dyslipidemia [2], has been implicated as the contributing factors to the development of cardiovascular diseases and type 2 diabetes [3]. On the other hand, recent studies showed that impaired pulmonary function is associated with all-cause and cardiovascular mortality [4], correlated with smoking and the components of MetS including obesity [5], type 2 diabetes [6], and insulin resistance [7].

As the components of MetS share partially overlapping pathophysiological mechanisms of common metabolic pathways, giving the MetS a significant potential for predicting lung function. Positive relationships between impaired lung function and MetS have been shown in cross-sectional studies [8, 9]. Similar associations 
between the components of the MetS with lung function impairment have also been reported in large cohort studies [10]. Furthermore, dyslipidemia has been observed as a biomarker of abnormal lung function [10,11], obesity was inversely related to lung function [12], and fasting serum insulin levels were also negatively correlated with lung function. Recent studies have provided evidence indicating that MetS predicted a steeper $\mathrm{FEV}_{1}$ decline over time [10] and was associated with a restrictive ventilatory pattern in patients with the high waist circumference (WC) [13].

The results of previous studies conducted in Italy, Taiwan and Japan all suggested that MetS was independently associated with restrictive pattern of impaired pulmonary function $[8,13,14]$. The findings of other reports were also congruent, revealing that restrictive lung disease (RLD) was related with MetS [15]. A cross-sectional study with a small sample size reported that a restrictive, but not an obstructive, respiratory pattern was associated with MetS and insulin resistance in elderly people [15]. One study with a large sample size from nationwide health screening centers in Taiwan also demonstrated that obesity and MetS were associated with restrictive lung impairment [8]. Another study that measured the spirometric parameters and MetS in healthy Korean adults without overt impaired lung function also showed an inverse relationship between lung function and MetS [9].

Abdominal obesity was a major factor that determined the association between MetS and pulmonary function impairment [9]. A review of studies on physiology of obesity and its effects on pulmonary function has suggested that central obesity is more likely to affect pulmonary volumes, even without direct effects on pulmonary obstruction [16]. However, large-scale study in Asians are scare; therefore, the aims of the current study were to explore the associations of MetS components with the lung function and to compare differences between genders and age in an adult population of Taiwan.

\section{Methods}

\section{Population}

This was a cross-sectional study including the adults aged $\geq 18$ years who attended annual health examination at three medical centers of the Chang-Gung Memorial Hospital during 2010-2012, including the Linkou Branch (northern Taiwan), and Chiayi Branch and Kaohsiung Branch (southern Taiwan). The study was approved by the Institutional Review Board of Chang-Gung Memorial Hospital and conducted in accordance with the guidelines laid down in the Declaration of Helsinki.
Participants with missing data or the following criteria were excluded from the analysis: (1) without a minimum of 12-h fasting prior to blood sampling; (2) pregnant women; (3) diagnosed with chronic diseases that can significantly affect metabolic and/or pulmonary functions, such as thyroid diseases, congestive heart failure, chronic hepatitis, liver cirrhosis, hypothalamus disease, asthma, tuberculosis, and lung cancer.

\section{Data collection and measurements}

The participants were surveyed about their lifestyle (smoking and drinking), medical history (disease and medication histories), and physiological conditions (including pregnancy and fasting time) during health examination. Trained nurses adhering to the standard operating procedures (SOP) were responsible for taking venous blood and collecting data using questionnaires. Estimates of self-reported smoking and physical exercise habits were obtained from questionnaire responses. The participants were classified as never smokers, former smokers, and current smokers. Current smokers included regular smokers with consumption of cigarette $\geq 1$ per day and light/intermittent/occasional smokers with 1-2 times/week. Former smokers were defined as having or ever smoked $\geq 100$ cigarettes in their lifetime. All information was coded electronically on a central record database.

Clinical chemistry workup included fasting plasma glucose (FPG), total cholesterol (TChol), triglycerides (TG), and HDL cholesterol (HDL-C). Blood tests were carried out according to the SOP of hospital laboratory accredited by the College of American Pathologists (CAP). Blood pressure (BP), height, weight, and WC were measured using the calibrated instruments. BP was measured three times using an automated sphygmomanometer after the participant was in the seated position for at least $15 \mathrm{~min}$. The mean arterial pressure (MAP) was estimated by using an approximation equation: $2 / 3 \times$ diastolic pressure $+1 / 3 \times$ systolic pressure. Height and weight were measured to the nearest $0.1 \mathrm{~cm}$ and $0.1 \mathrm{~kg}$. Body mass index (BMI) was calculated as weight divided by height squared $\left(\mathrm{kg} / \mathrm{m}^{2}\right)$.

\section{Assessment of lung function}

Lung function was determined using a dry rolling seal spirometer (Medical International Research, Rome, Italy). Spirometric parameters were measured by technicians who had been trained according to the definitions of the American Thoracic Society [17]. Only data from the participants with three or more acceptable spirometry tests were analyzed. Values measured in this study were forced vital capacity (FVC), forced expiratory volume in $1 \mathrm{~s}\left(\mathrm{FEV}_{1}\right)$, and $\mathrm{FEV}_{1}$ to $\mathrm{FVC}$ ratio $\left(\mathrm{FEV}_{1} / \mathrm{FVC}\right)$. RLD was defined as 
$\mathrm{FVC}<80 \%$ and $\mathrm{FEV}_{1} / \mathrm{FVC}>70 \%$ of predicted value. Participants with $\mathrm{FEV}_{1} / \mathrm{FVC}<70 \%$ of predicted values were assigned as having obstructive lung disease (OLD).

\section{Assessment of metabolic syndrome}

Participants with MetS were identified according to the criteria proposed by the National Cholesterol Education Program (NCEP) Adult Treatment Panel III [18], as having three or more of the following risk factors: (1) BP of 130/ $85 \mathrm{mmHg}$ or higher, (2) TG of $1.7 \mathrm{mmol} / \mathrm{L}$ or higher $(150 \mathrm{mg} / \mathrm{dL})$, (3) HDL-C of $<1.0 \mathrm{mmol} / \mathrm{L}(40 \mathrm{mg} / \mathrm{dL})$ for men and $<1.3 \mathrm{mmol} / \mathrm{L}(50 \mathrm{mg} / \mathrm{dL})$ for women, (4) fasting glucose of $6.1 \mathrm{mmol} / \mathrm{L}$ or higher $(110 \mathrm{mg} / \mathrm{dL})$, and $(5)$ abdominal obesity as defined by Asia-Pacific cutoff limits (waist circumference $\geq 90 \mathrm{~cm}$ for men and $\geq 80 \mathrm{~cm}$ for women) [19].

\section{Statistical analysis}

Parametric continuous variables were expressed as mean \pm standard deviation (SD). Categorical data were expressed in number (percentage). Differences were tested by chi-square test for categorical variables and one-way analysis of variance (ANOVA) for continuous variables. The relationships between lung function (specifically spirometric parameters) and MetS risk factors were explored using linear regression. The relationships between RLD and scores of MetS were determined using binary logistic regression. Potential confounding factors, including age, smoking, and BMI were adjusted to assess the associations. All analyses were conducted using SPSS version 16.0 (SPSS, Chicago, IL, USA). A two-sided $p$ value $<0.05$ was considered statistically significant.

\section{Results}

A total of 6945 subjects (5334 males and 1611 females) were included for analysis (Table 1). Females were significantly younger than males (mean ages, $34.7 \pm 8.0$ vs. $38.1 \pm 8.2, p<0.001)$. The prevalence of smoking was significantly higher in males than females. Significant differences in all clinical characteristics were observed between genders (all $p$ values $<0.001$ ). Compared to females, males had greater WC $(85.1 \pm 9.2$ vs. $74.0 \pm$ $10.0 \mathrm{~cm})$, higher levels of SBP $(128.6 \pm 14.8$ vs. $114.5 \pm$ $14.3 \mathrm{mmHg})$, DBP $(81.1 \pm 10.5$ vs. $73.1 \pm 9.5 \mathrm{mmHg})$, FPG $(93.8 \pm 11.3$ vs. $88.4 \pm 15.6 \mathrm{mg} / \mathrm{dL})$, TChol $(188.3 \pm 34.3$ vs. $178.2 \pm 31.2 \mathrm{mg} / \mathrm{dL})$, and TG $(138.0 \pm 138.4$ vs. $82.9 \pm$ $46.0 \mathrm{mg} / \mathrm{dL})$, but lower HDL-C $(50.1 \pm 11.9$ vs. $60.4 \pm$ $13.6 \mathrm{mg} / \mathrm{dL}$ ). The prevalence of MetS was significantly higher in males than females. Despite there was no gender
Table 1 Basic characteristics of the study subjects $(n=6945)$

\begin{tabular}{|c|c|c|c|}
\hline Characteristics & $\begin{array}{l}\text { Males } \\
(n=5334)\end{array}$ & $\begin{array}{l}\text { Females } \\
(n=1611)\end{array}$ & $p$ value \\
\hline Age, y & $38.1 \pm 8.2$ & $34.7 \pm 8.0$ & 0.000 \\
\hline Smoking & & & 0.000 \\
\hline Current smoker, $n(\%)$ & $1834(34.4)$ & $161(10.0)$ & 0.000 \\
\hline Former smoker, $n(\%)$ & $543(10.2)$ & $25(1.6)$ & 0.000 \\
\hline $\mathrm{WC}, \mathrm{cm}$ & $85.1 \pm 9.2$ & $74.0 \pm 10.0$ & 0.000 \\
\hline WHtR & $0.50 \pm 0.05$ & $0.46 \pm 0.06$ & 0.000 \\
\hline BMI & $24.8 \pm 5.4$ & $22.4 \pm 4.1$ & 0.000 \\
\hline $\mathrm{SBP}, \mathrm{mmHg}$ & $128.6 \pm 14.8$ & $114.5 \pm 14.3$ & 0.000 \\
\hline $\mathrm{DBP}, \mathrm{mmHg}$ & $81.1 \pm 10.5$ & $73.1 \pm 9.5$ & 0.000 \\
\hline MAP, $\mathrm{mmHg}$ & $96.9 \pm 11.3$ & $86.9 \pm 10.6$ & 0.000 \\
\hline FPG $(\mathrm{mg} / \mathrm{dL})$ & $93.8 \pm 20.0$ & $88.4 \pm 15.6$ & 0.000 \\
\hline TChol (mg/dL) & $188.3 \pm 34.3$ & $178.2 \pm 31.2$ & 0.000 \\
\hline $\mathrm{TG}(\mathrm{mg} / \mathrm{dL})$ & $138.0 \pm 138.4$ & $82.9 \pm 46.0$ & 0.000 \\
\hline HDL-C (mg/dL) & $50.1 \pm 11.9$ & $60.4 \pm 13.6$ & 0.000 \\
\hline TG/HDL-C & $3.2 \pm 5.4$ & $1.5 \pm 1.5$ & 0.000 \\
\hline MetS, $n(\%)$ & $865(16.2)$ & $61(3.8)$ & 0.000 \\
\hline FVC (\% predicted) & $91.8 \pm 21.2$ & $93.3 \pm 33.3$ & 0.098 \\
\hline $\mathrm{FEV}_{1}(\%$ predicted $)$ & $94.4 \pm 13.4$ & $94.1 \pm 14.0$ & 0.372 \\
\hline $\mathrm{FEV}_{1} / \mathrm{FVC}$ ratio & $94.4 \pm 12.4$ & $91.7 \pm 9.6$ & 0.000 \\
\hline
\end{tabular}

Continuous data are shown as mean \pm SD and compared using independent sample $t$ tests. Categorical data are shown as $n(\%)$ and compared using the chi-square test

$W C$ waist circumference, $W H t R$ waist-to-height ratio, $B M I$ body mass index, $S B P$ systolic blood pressure, $D B P$ diastolic blood pressure, $M A P$ mean arterial pressure, $F P G$ fasting plasma glucose, $T C h o l$ total cholesterol, $T G$ triglycerides, $H D L-C$ HDL cholesterol, MetS metabolic syndrome, $F V C$ forced vital capacity, $F E V_{l}$ forced expiratory volume in $1 \mathrm{~s}$

difference in the mean estimates of FVC (\% predicted) and $\mathrm{FEV}_{1}(\%$ predicted), males had a significantly higher mean $\mathrm{FEV}_{1} / \mathrm{FVC}$ ratio.

Table 2 shows the independent relationships between each component of MetS and FVC (\% predicted) and $\mathrm{FEV}_{1} /$ FVC ratio by multiple linear regression analyses. WC was significantly negatively associated with $\mathrm{FVC}$ in males aged $\leq 45$ years. A significant negative correlation between WHtR and FVC was observed in females aged $>45$ years. The relationships between TChol and TG with FVC were weak in males aged $\leq 45$ years and not observed in those aged $>45$ years. HDL-C was also only weakly related with FVC in the male participants aged $>45$ years.

WC showed a significant negative correlation with $\mathrm{FEV}_{1} / \mathrm{FVC}$ ratios in all males and females aged $\leq 45$ years. A strong positive relationship between WHtR and $\mathrm{FEV}_{1} /$ FVC ratios were detected in males aged $\leq 45$; however, a significant inverse relationship was found for females aged $>45$ years. Although there were some statistically 


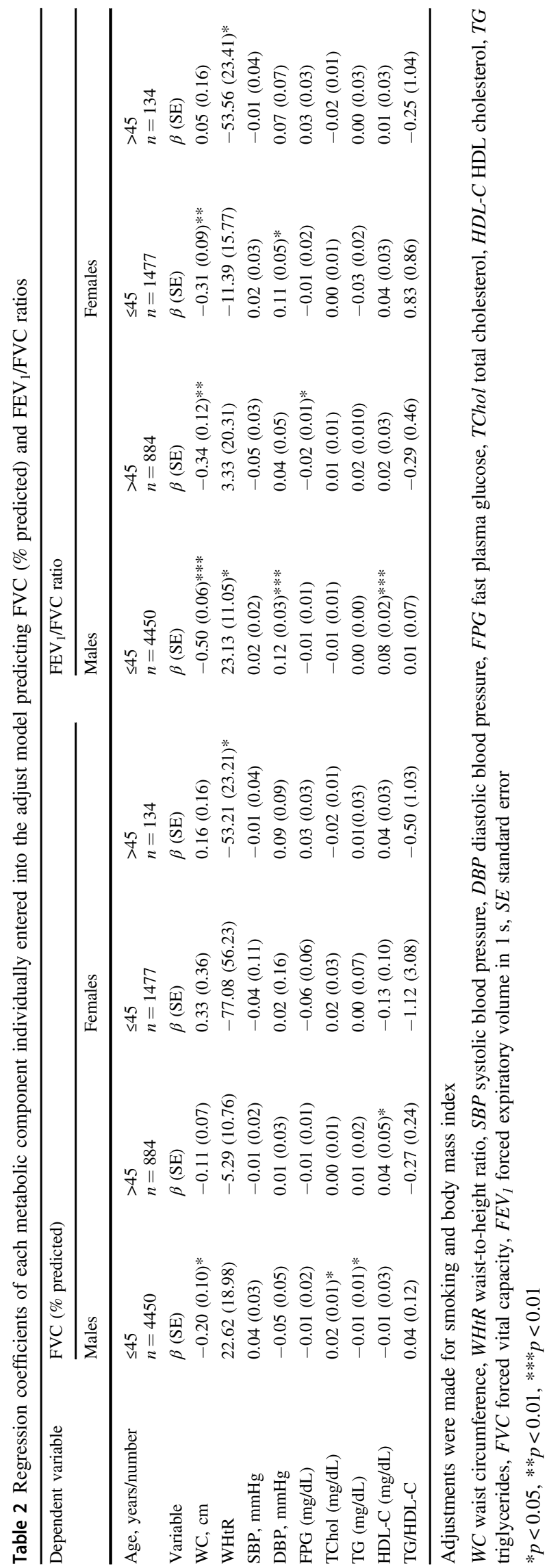

significant relationships between DBP, FPG, and HDL-C with $\mathrm{FEV}_{1} / \mathrm{FVC}$ ratios, the relationships were all very weak.

The overall RLD prevalence was comparable between males $(20.7 \%, 1156 / 5334)$ and females $(21.0 \%, 339 / 1611)$. However, the prevalence of RLD with coexistent MetS was higher in males $(27.4 \%, 237 / 865)$ than females $(18.0 \%, 11 /$ 61, Table 3). As the number of participants with OLD was too small $(n=28$ in males and $n=9$ in females, data not shown) for statistical analysis, only the associations between the number of MetS components [18] and lung function according to the criteria for RLD were determined. There was a trend toward an increased prevalence of RLD with the increasing number of MetS scores for males (Fig. 1a, from 17.8 to $27.4 \%$ ), and the increasing ORs for RLD were independent of age, smoking, and BMI (Fig. 1b).

Although the prevalence of RLD in males with MetS was higher than those without MetS; however, RLD was not associated with increased probability of having MetS among males after adjustment for smoking and BMI (Table 3). RLD increased the likelihood of having MetS for females aged $>$ 45 years; however, it did not reach statistical significance (Table 3). RLD prevalence in females was not associated with the increasing number of MetS scores (Fig. 1a) and the relationships were not statistically significant after adjusting confounding factors, despite increasing with MetS scores (Fig. 1c).

\section{Discussion}

Some potential limitations of this study should be addressed before interpreting our findings. First, our study was limited to a relatively healthy population of prime adults, and thus cannot be considered representative of subjects aged older. Second, our findings were obtained in the Chinese population; hence, the findings of negative association between FCV and WC only in men aged $<45$ years may be varied by different ethnic groups and less generalizable to other populations. Third, although estrogen may modify and affect pulmonary function in women [5], the limited number of cases aged $>45$ years precluded us from analyzing the associations. Fourth, the cross-sectional design of our study precludes any conclusion about the causal relationship between MetS and the development of pulmonary function impairment.

On the basis of the $\mathrm{FEV}_{1} / \mathrm{FVC}$ ratio, the findings of this study indicated that WC, after adjusting smoking status and BMI, was the most significant predictor among the MetS components associated with lung function decline in both males and females aged $\leq 45$ years. WHtR was found to be a prominent and independent predictor of lung function decline in females aged $>45$ years. Taking together, our study suggested that abdominal obesity was associated with 
Table 3 Odds ratios (ORs) of restrictive lung disease (RLD) in predicting metabolic syndrome (MetS)
Fig. 1 Relationships between RLD and MetS scores. a The $(n=1156)$ and females $(n=$ 339) with various MetS scores. The numbers of males with RLD and $0,1,2$, and 3+ MetS scores were $298,357,264$, and 237 ; females, 229, 73, 26, 11, respectively. The association between RLD and MetS scores in males (b) and females (c) according to odd ratios (OR). Model 1: adjusted for age and smoking; model 2: adjusted for restrictive lung disease, MetS metabolic syndrome, BMI body mass index prevalence of RLD in the males age, smoking, and BMI. RLD

\begin{tabular}{|c|c|c|c|c|}
\hline \multirow[b]{2}{*}{ Male } & \multicolumn{2}{|l|}{$\leq 45$ years } & \multicolumn{2}{|l|}{$>45$ years } \\
\hline & MetS $(n=3771)$ & MetS $(n=679)$ & MetS $(n=698)$ & MetS $(n=186)$ \\
\hline $\mathrm{RLD}, n(\%)$ & $834(22.1 \%)$ & $203(29.9 \%)$ & $85(12.1 \%)$ & $34(18.2 \%)$ \\
\hline Crude OR $(95 \% \mathrm{CI})$ & Reference & $0.67(0.56-0.80)^{* * *}$ & Reference & $0.62(0.40-0.96)^{*}$ \\
\hline \multicolumn{5}{|l|}{ Adjust OR (95\% CI) } \\
\hline Model 1 & Reference & $0.66(0.55-0.79)^{* * *}$ & Reference & $0.63(0.41-0.98)^{*}$ \\
\hline Model 2 & Reference & $0.65(0.53-0.81)^{* *}$ & Reference & $0.83(0.51-1.37)$ \\
\hline Female & MetS $(n=1424)$ & MetS $(n=52)$ & MetS $(n=126)$ & MetS $(n=9)$ \\
\hline $\mathrm{RLD}, n(\%)$ & $321(22.5 \%)$ & $9(17.3 \%)$ & $7(5.6 \%)$ & $2(22.2 \%)$ \\
\hline Crude OR $(95 \%$ CI) & Reference & $0.70(0.34-1.46)$ & Reference & $5.67(0.96-33.35)$ \\
\hline \multicolumn{5}{|l|}{ Adjust OR (95\% CI) } \\
\hline Model 1 & Reference & $0.85(0.68-1.05)$ & Reference & $5.23(0.90-31.13)$ \\
\hline Model 2 & Reference & $1.11(0.51-2.41)$ & Reference & $4.52(0.68-29.81)$ \\
\hline
\end{tabular}

Data were calculated using multiple logistic regression

Model 1: adjusted for smoking

Model 2: adjusted for smoking and body mass index

$* p<0.05 ; * * p<0.01 ; * * * p<0.001$
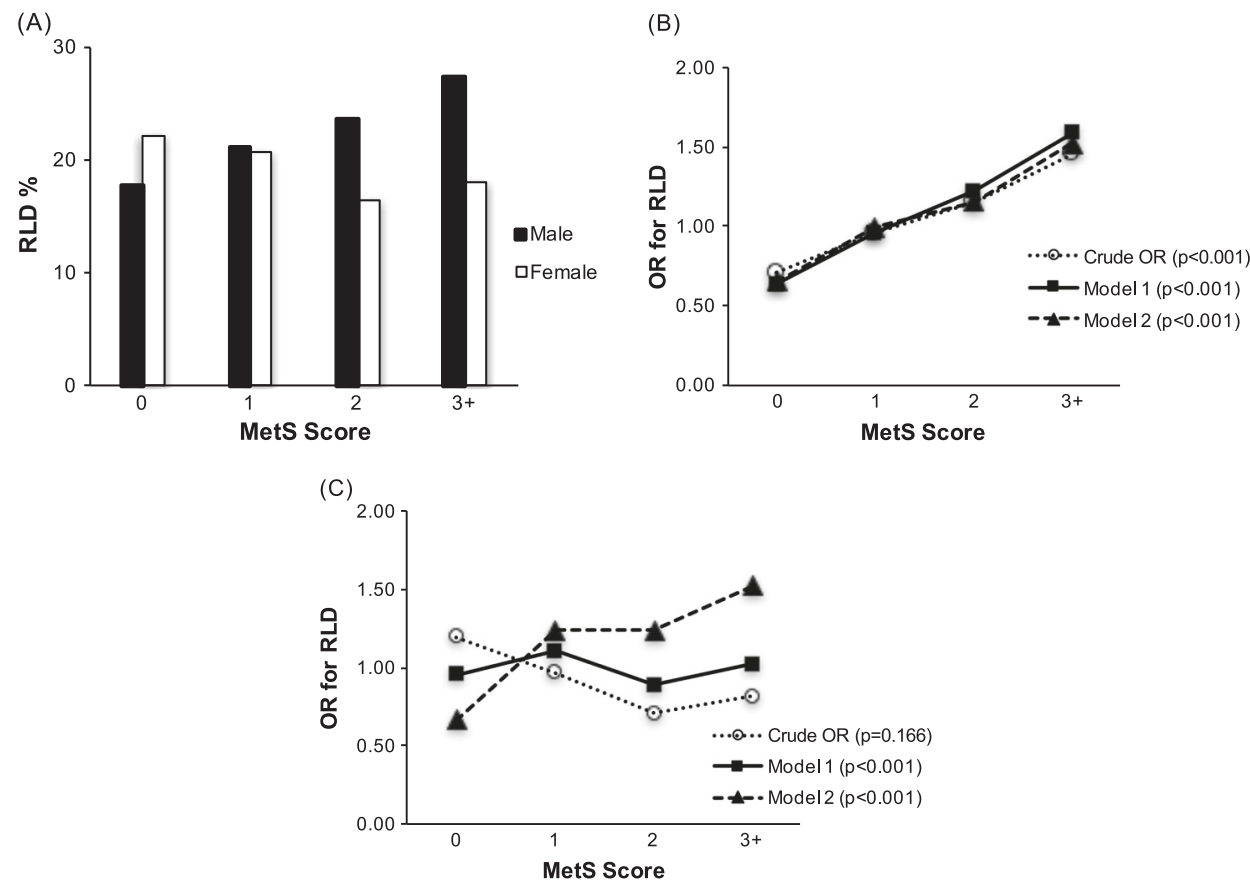

increased probability of losing lung function in this primeage adult population.

Our results were comparable with the findings of previous studies showing that abdominal obesity was the most power predictor of poor pulmonary function $[9,13,20]$. Epidemiological studies in adults have also shown that WC, one of the indicators of abdominal adiposity, is a risk factor for pulmonary function deterioration $[21,22]$. The underlying mechanisms are associated with excess adipose tissue within abdominal region that exerts a mechanical effect on the lungs, by reducing the capacity of the diaphragm to limit lung inflation, consequently diminishes the chest wall movement [16]. Body fat distributions in men, pre- and postmenopausal women were different, where males generally accumulate more abdominal body fat whereas premenopausal women develop larger lower body fat. Menopause is associated with fat deposition shift to visceral depot and correlated to rapid onset of the metabolic syndrome [23, 24]. Adipose tissue function and deposition differ by gender. Females have more subcutaneous fat prior to menopause and postmenopausal women can have up to twice the amount of visceral adipose tissue than 
premenopausal women [25]; it is therefore interesting to investigate the relationships between lung function deterioration and the loss of the hormonal protective environment after menopause and the negative effects related to different fat distribution.

Furthermore, our results added to the existing evidence in a recent meta-analysis of more than 500 studies that showed an inverse relationship between WC and lung function parameters, a greater effect of WC among men compared to women, and central obesity is possibly associated with restrictive patterns, but not airways obstruction [26]. Central obesity may affect ventilator mechanics because it limits diaphragm expansion [16]. The gender differences might be associated with breathing movements of the chest and abdominal wall [27] and fat distribution that affect pulmonary function differently for women and men [28]. By contrast, there are some inconsistencies that exist between our findings and other studies. Chen et al. found negative correlations between $\mathrm{FEV}_{1} / \mathrm{FVC}$ and $\mathrm{WC}$ for both males and females after adjustments for age, height, weight, workload, energy consumption, and smoking [29]. While we observed similar trend except for females over aged $>45$ years.

Although the prevalence of RLD was higher in males with MetS, RLD was not associated with increased probability for MetS in this study. However, there were gender differences in the relationships between lung function and the number of MetS scores, as well as MetS score in predicting RLD. The odds of RLD were positively related with the number of MetS scores, independent of age, smoking, and BMI for males. Similar results were not observed in females, because insufficient case number limited the analysis and interpretation. Our results were consistent with a previous study reporting the prevalence of MetS was independently associated with RLD in Taiwanese population [8]. Notably, we found remarkable increases in the prevalence of RLD (overall 21.5 vs. 12.7\%) and MetS (overall, 13.4 vs. $5.8 \%$ ) in the Taiwanese population when compared to 10-12 years ago [8].

Our findings were also in line with the study that reported a correlation between FVC and MetS level and an increase in the severity of MetS impairs lung function in men but not in women among the Japanese population [14]. The results of a cross-sectional population-based study in France also demonstrated that people with more MetS factors are more vulnerable to restrictive pulmonary function impairment [9]. However, inconsistent findings were reported in a study of Koreans, in which no association was found between the number of MetS components and $\mathrm{FEV}_{1} / \mathrm{FVC}$ [20].

Although the mechanisms underlying the MetS increases the odds of having RLD remain to be clarified, factors such as WC [12, 21, 22], dyslipidemia, insulin resistance [9, 30], leptin, and chronic inflammation $[4,31,32]$ may function as biomarkers of increased susceptibility. However, lung function impairment is developed through multiple and simultaneous mechanisms; prediction using any of these biomarkers should be taken with precautions and should also highlight the importance of MetS in lung function. Particularly, compared with Caucasians, Asians tend to have a higher percentage of body fat and a tendency to more central obesity $[15,33,34]$ and that are the most possible mechanisms contributing to airflow limitation [35] and consequent restrictive respiration impairment [22]. Despite this, we know little to adequately quantify central obesity leading to health burden associated with lung function impairment; public health intervention targeted to prevent this modifiable factor might be taken into consideration.

In conclusion, the results of this study demonstrated that abdominal obesity was the key MetS component associated with mechanical effects on lung function impairment in a prime-age adult population. Our study provided an insight on how obesity contributes to the development of lung function decline and the interplay between MetS and lung function. RLD was not associated with increased probability of having MetS. Risk of losing lung function was greater in the participants with more MetS scores. Because there are relatively few women with metabolic syndrome over the age of 45 , the weaker association among women requires further research to draw conclusion.

Acknowledgements The authors would like to thank the staff of the Health Examination Centers in the Linkou, Chiayi, and Kaohsiung branches of Cheng Gung Memorial Hospital for assistance with data collection.

Author contributions Y-YL: contributed to the concept and design of the study, data analysis, drafting of the manuscript, and conducting the study. Y-CT: contributed to subject enrollment, conducting the required measurements, and reviewing the manuscript. C-KY: contributed to conducting the required measurements and data analysis. C$\mathrm{HC}$ : contributed to subject enrollment and conducting the required measurement. WY: contributed to subject enrollment and conducting the required study testing and interventions. J-CC: contributed to conducting the required study testing and interventions, and reviewing the manuscript. W-CL: contributed to the concept and design of the study and revising the manuscript.

\section{Compliance with ethical standards}

Conflict of interest The authors declare that they have no conflict of interest.

Publisher's note: Springer Nature remains neutral with regard to jurisdictional claims in published maps and institutional affiliations.

\section{References}

1. Pan WH, Yeh WT, Weng LC. Epidemiology of metabolic syndrome in Asia. Asia Pac J Clin Nutr. 2008;17(Suppl 1):37-42. 
2. Grundy SM, Cleeman JI, Daniels SR, Donato KA, Eckel RH, Franklin BA, et al. Diagnosis and management of the metabolic syndrome: an American Heart Association/National Heart, Lung, and Blood Institute Scientific Statement. Circulation. 2005;112:2735-52.

3. Lakka HM, Laaksonen DE, Lakka TA, Niskanen LK, Kumpusalo E, Tuomilehto J, et al. The metabolic syndrome and total and cardiovascular disease mortality in middle-aged men. JAMA. 2002;288:2709-16.

4. Sin DD, Wu L, Man SF. The relationship between reduced lung function and cardiovascular mortality: a population-based study and a systematic review of the literature. Chest. 2005;127:1952-9.

5. McClean KM, Kee F, Young IS, Elborn JS. Obesity and the lung: 1. Epidemiol Thorax. 2008;63:649-54.

6. Yeh HC, Punjabi NM, Wang NY, Pankow JS, Duncan BB, Brancati FL. Vital capacity as a predictor of incident type 2 diabetes: the Atherosclerosis Risk in Communities study. Diabetes Care. 2005;28:1472-9.

7. Lawlor DA, Ebrahim S, Smith GD. Associations of measures of lung function with insulin resistance and Type 2 diabetes: findings from the British Women's Heart and Health Study. Diabetologia. 2004;47:195-203.

8. Lin WY, Yao CA, Wang HC, Huang KC. Impaired lung function is associated with obesity and metabolic syndrome in adults. Obesity (Silver Spring). 2006;14:1654-61.

9. Leone N, Courbon D, Thomas F, Bean K, Jego B, Leynaert B, et al. Lung function impairment and metabolic syndrome: the critical role of abdominal obesity. Am J Respir Crit Care Med. 2009;179:509-16.

10. Naveed B, Weiden MD, Kwon S, Gracely EJ, Comfort AL, Ferrier N, et al. Metabolic syndrome biomarkers predict lung function impairment: a nested case-control study. Am J Respir Crit Care Med. 2012;185:392-9.

11. Weiden MD, Kwon S, Caraher E, Berger KI, Reibman J, Rom WN, et al. Biomarkers of World Trade Center particulate matter exposure: physiology of distal airway and blood biomarkers that predict FEV(1) decline. Semin Respir Crit Care Med. 2015;36:323-33.

12. Canoy D, Luben R, Welch A, Bingham S, Wareham N, Day N, et al. Abdominal obesity and respiratory function in men and women in the EPIC-Norfolk Study, United Kingdom. Am J Epidemiol. 2004;159:1140-9.

13. Fimognari FL, Pasqualetti P, Moro L, Franco A, Piccirillo G, Pastorelli $\mathrm{R}$, et al. The association between metabolic syndrome and restrictive ventilatory dysfunction in older persons. J Gerontol A Biol Sci Med Sci. 2007;62:760-5.

14. Nakajima K, Kubouchi Y, Muneyuki T, Ebata M, Eguchi S, Munakata $\mathrm{H}$. A possible association between suspected restrictive pattern as assessed by ordinary pulmonary function test and the metabolic syndrome. Chest. 2008;134:712-8.

15. Kohli S, Sniderman AD, Tchernof A, Lear SA. Ethnic-specific differences in abdominal subcutaneous adipose tissue compartments. Obesity (Silver Spring). 2010;18:2177-83.

16. Salome CM, King GG, Berend N. Physiology of obesity and effects on lung function. J Appl Physiol (1985). 2010;108:206-11.

17. Standardization of Spirometry. 1994 Update. American Thoracic Society. Am J Respir Crit Care Med. 1995;152:1107-36.

18. Expert Panel on Detection E, Treatment of High Blood Cholesterol in A. Executive Summary of The Third Report of The
National Cholesterol Education Program (NCEP) Expert Panel on Detection, Evaluation, And Treatment of High Blood Cholesterol In Adults (Adult Treatment Panel III). JAMA. 2001;285:2486-97.

19. WHO. World Health Organization Western Pacific Region, IAftSoO, and International Obesity Taskforce. The Asian-Pacific Perspective: Redefining Obesity and Its Treatment. (WHO, Geneva, 2000).

20. Paek YJ, Jung KS, Hwang YI, Lee KS, Lee DR, Lee JU. Association between low pulmonary function and metabolic risk factors in Korean adults: the Korean National Health and Nutrition Survey. Metabolism. 2010;59:1300-6.

21. Ochs-Balcom HM, Grant BJ, Muti P, Sempos CT, Freudenheim JL, Trevisan M, et al. Pulmonary function and abdominal adiposity in the general population. Chest. 2006;129:853-62.

22. Chen Y, Rennie D, Cormier YF, Dosman J. Waist circumference is associated with pulmonary function in normal-weight, overweight, and obese subjects. Am J Clin Nutr. 2007;85:35-9.

23. Lobo RA. Metabolic syndrome after menopause and the role of hormones. Maturitas. 2008;60:10-8.

24. Kanaley JA, Sames C, Swisher L, Swick AG, Ploutz-Snyder LL, Steppan CM, et al. Abdominal fat distribution in pre- and postmenopausal women: the impact of physical activity, age, and menopausal status. Metabolism. 2001;50:976-82.

25. Tchernof A, Despres JP. Pathophysiology of human visceral obesity: an update. Physiol Rev. 2013;93:359-404.

26. Wehrmeister FC, Menezes AM, Muniz LC, Martinez-Mesa J, Domingues MR, Horta BL. Waist circumference and pulmonary function: a systematic review and meta-analysis. Syst Rev. 2012;1:55.

27. Kaneko H, Horie J. Breathing movements of the chest and abdominal wall in healthy subjects. Respir Care. 2012;57:1442-51.

28. Harik-Khan RI, Wise RA, Fleg JL. The effect of gender on the relationship between body fat distribution and lung function. $\mathrm{J}$ Clin Epidemiol. 2001;54:399-406.

29. Chen R, Tunstall-Pedoe H, Bolton-Smith C, Hannah MK, Morrison C. Association of dietary antioxidants and waist circumference with pulmonary function and airway obstruction. Am J Epidemiol. 2001;153:157-63.

30. Klein OL, Krishnan JA, Glick S, Smith LJ. Systematic review of the association between lung function and Type 2 diabetes mellitus. Diabet Med. 2010;27:977-87.

31. Hotamisligil GS. Inflammation and metabolic disorders. Nature. 2006;444:860-7.

32. Hickson DA, Burchfiel CM, Petrini MF, Liu J, Campbell-Jenkins $\mathrm{BW}$, Bhagat R, et al. Leptin is inversely associated with lung function in African Americans, independent of adiposity: the Jackson Heart Study. Obesity (Silver Spring). 2011;19:1054-61.

33. Lear SA, Humphries KH, Kohli S, Chockalingam A, Frohlich JJ, Birmingham CL. Visceral adipose tissue accumulation differs according to ethnic background: results of the Multicultural Community Health Assessment Trial (M-CHAT). Am J Clin Nutr. 2007;86:353-9.

34. Rush EC, Freitas I, Plank LD. Body size, body composition and fat distribution: comparative analysis of European, Maori, Pacific Island and Asian Indian adults. Br J Nutr. 2009;102:632-41.

35. Rossi A, Fantin F, Di Francesco V, Guariento S, Giuliano K, Fontana G, et al. Body composition and pulmonary function in the elderly: a 7-year longitudinal study. Int $\mathrm{J}$ Obes (Lond). 2008;32:1423-30. 